\title{
Produção de alface com doses de lodo de esgoto
}

\author{
José Carlos Lopes; Luiz G. Ribeiro; Marcelo G. de Araújo; Marcela Regina B.S. Beraldo
}

UFES, CCA, Depto. Fitotecnia, 29500-000 Alegre-ES; E-mail: sementes@npd.ufes.br

\section{RESUMO}

Avaliou-se a produção de alface em solo tratado com doses de lodo de esgoto como fonte de matéria orgânica em experimento em casa de vegetação da Universidade Federal do Espírito Santo. o delineamento experimental foi inteiramente casualizado, com cinco repetições e os tratamentos: solo sem adubação (testemunha) e solo+lodo de esgoto em doses crescentes de 33,3; 66,6; 99,9 e 133,2 $\mathrm{g} \mathrm{dm}^{-3} \mathrm{em}$ base seca. As plantas foram cultivadas, individualmente, em vasos contendo $6 \mathrm{dm}^{3}$ de substrato. $O$ crescimento da parte aérea e o aumento de matéria fresca nas folhas das plantas foram estatisticamente superiores ao controle e a regressão indica a possibilidade da utilização de doses mais elevadas de lodo de esgoto.

Palavras-chave: Lactuca sativa L., biossólidos, resíduos, metais pesados.

\begin{abstract}
Lettuce production using doses of sewage sludge

The lettuce production was evaluated in soil treated with sewage sludge as source of organic matter. The experiment was carried out in the greenhouse of the Universidade Federal do Espirito Santo, Espirito Santo State, Brazil, in a complete randomized design with five replications. Plants were grown in plastic pots with $6 \mathrm{dm}^{3}$ of soil mixture using sewage sludge in increasing doses of $0 ; 33.3$; 66.6; 99.9 and $133.2 \mathrm{~g} \mathrm{dm}^{-3}$. The development of lettuce plants in soil treated with sewage sludge differed significantly from the control and the regression suggests the possibility of use of larger doses of sewage sludge in the lettuce production.
\end{abstract}

Keywords: Lactuca sativa L., biosolid, residues, weighed metals.

\section{(Recebido para publicação em 14 de janeiro de 2004 e aceito em 2 de dezembro de 2004)}

\section{A} alface (Lactuca sativa L.) é a hortaliça folhosa de maior valor comercial cultivada no Brasil, com cerca de setenta e cinco cultivares comerciais, das quais, aproximadamente dezoito são nacionais. É consumida, com maior freqüência, em saladas cruas e sanduíches, sendo que as regiões Sul e Sudeste são as maiores consumidoras. É considerada planta de propriedades tranqüilizantes, com alto conteúdo de vitaminas A, $\mathrm{B}$ e $\mathrm{C}$, além de cálcio, fósforo, potássio e outros minerais (Viggiano, 1990). A planta é exigente nas características físicas e químicas do solo. Por ser de ciclo curto e hortaliça cuja parte consumida são as folhas, responde ao fornecimento de nitrogênio. O solo ideal para o seu cultivo é o areno-argiloso, rico em matéria orgânica e nutrientes (Ferreira et al., 1993; Filgueira, 2000). A adubação orgânica com estercos de animais e compostos orgânicos tem sido amplamente utilizada na produção de alface, com o objetivo de reduzir as quantidades de fertilizantes químicos e melhorar as qualidades físicas, químicas e biológicas do solo (Kiehl, 1985; Silva et al., 2001). Sua utilização tem proporcionado aumento na produção e no teor de nutrientes em plantas de alface (Santos, 1993; Ricci, et al., 1994; Vidigal et al, 1995; Santos et al., 1997;
Vidigal et al., 1997; Rodrigues e Casali, 1998).

Santos et al. (1999), trabalhando com composto orgânico de lixo urbano na cultura da alface, verificaram acréscimo no conteúdo de matéria orgânica do solo. Por outro lado, a utilização de adubo orgânico para fertilizar o solo aumenta a capacidade de troca de cátions (CTC), a porosidade e a aeração, com redução do encrostamento da sua superfície, proporcionando maior volume de água disponível, devido à melhoria das condições físicas do solo (Kiehl, 1985; Raij, 1987). Ferraz Junior et al. (2003) verificaram que a aplicação de lodo de cervejaria na cultura da alface proporcionou aumento nos teores de fósforo e nos valores de $\mathrm{pH}$ do solo, com efeitos similares àqueles obtidos com esterco de galinha. O manejo da matéria orgânica num sistema de produção é essencial, já que ela é uma das principais fontes de reservas de $\mathrm{N}$ e responde por grande parte da CTC do solo, cerca de $56 \%$ a $82 \%$ nos solos tropicais (Raij, 1969).

A disposição final do lodo de Estação de Tratamento de Esgoto (ETE) é uma preocupação mundial, em razão do crescente volume produzido. A utilização agrícola deste resíduo já ocorre atualmente em muitos países. O siste- ma de coleta e tratamento de esgotos domésticos é um dos pressupostos básicos para um ambiente saudável, garantindo qualidade de vida e preservação do meio ambiente. Para a reciclagem agrícola do lodo de esgoto, é necessário o conhecimento do impacto causado no meio biótico e abiótico pela sua utilização, bem como o estudo e aprimoramento de tecnologias que permitam a sua inserção nos sistemas agrícolas (Andreoli et al., 1997).

Estudando uma alternativa para a reutilização da água associada ao tratamento de esgoto doméstico, através do sistema de bacia de infiltração, Andreoli et al. (1999) demonstraram a possibilidade de sua utilização direta em irrigação de parques, jardins, campos de golfe e lagos artificiais, em processos industriais ou, indireta, na recarga de aqüíferos. Como adubo para produção de milho, Biscaia e Miranda (1996) verificaram que o lodo de esgoto pode ser empregado em doses de $60 \mathrm{t} \mathrm{ha}^{-1}$, não apresentando toxicidade ao desenvolvimento e produtividade da cultura. Em sistema de produção de bracatinga, na região metropolitana de Curitiba (PR), Lourenço et al. (1996) verificaram que o lodo de esgoto pode apresentar efeito residual para as culturas subseqüentes, quando empregado em doses elevadas. 
A utilização do lodo se defronta, contudo, com problemas como o aumento da concentração de metais pesados e de agentes patogênicos no solo. Os metais pesados são elementos que possuem peso específico maior do que $5 \mathrm{~g} \mathrm{~cm}^{-3}$ ou número atômico maior do que 20 (Malavolta, 1994). A quantidade de agentes patogênicos no lodo depende de sua origem, da época do ano e do processo de tratamento ao qual foi submetido. A utilização do lodo não higienizado como adubo orgânico em culturas com ciclo de vida curto, cujas partes comestíveis tenham contato direto com o solo e que sejam consumidas in natura apresenta grande risco para a saúde humana e animal. Para reduzir esse risco, o lodo deve ser tratado com os processos de digestão anaeróbia, calagem ou compostagem, antes de ser utilizado. A compostagem, quando bem controlada, pode melhorar as características físico-químicas do lodo urbano, podendo este ser posteriormente empregado para os mais variados fins. Os autores recomendam que o teor de matéria seca seja superior a $20 \%$ para se obter maior percentual de redução de ovos de helmintos (Soccol et al., 1999).

Este trabalho teve como objetivo avaliar a produção de alface em solo tratado com diferentes doses de lodo de esgoto como fonte de matéria orgânica.

\section{MATERIAL E MÉTODOS}

O trabalho foi desenvolvido de maio a dezembro de 1998, em casa de vegetação da UFES, localizada em Alegre (ES), mesoregião sul do estado, apresentando altitude de cerca de 250 metros.

O solo utilizado na composição dos substratos foi proveniente da camada arável de um Aluvial Eutrófico, textura média, amostrado na Área Experimental da UFES, e apresentou as seguintes características: $\mathrm{pH}=5,0 ; \mathrm{Al}^{3+}=0,10$ $\mathrm{cmol}_{\mathrm{c}} \mathrm{dm}^{-3} ; \mathrm{Ca}^{2+}=1,0 \mathrm{cmol}_{\mathrm{c}} \mathrm{dm}^{-3} ; \mathrm{Mg}^{2+}$ $=0,8^{\mathrm{c}} \mathrm{cmol}_{\mathrm{c}} \mathrm{dm}^{-3} ; \mathrm{P}=2,0 \mathrm{mg} \mathrm{dm}^{-3} ; \mathrm{K}=$ $0,15 \mathrm{cmol}_{\mathrm{c}} \mathrm{dm}^{-3}$ e $\mathrm{MO}=2,7 \mathrm{~g} \mathrm{~kg}^{-1}$. Antes de ser misturado, o solo foi peneirado em malha de $4 \mathrm{~mm}$, sendo a seguir adicionado calcário dolomítico (38\% $\mathrm{CaO}, 15 \%$ de $\mathrm{MgO}$ e PRNT de $88 \%$ ) na dose de $0,53 \mathrm{~g} \mathrm{dm}^{-3}$.
O lodo utilizado foi oriundo da ETE do município de Jerônimo Monteiro (sistema australiano). Foi feita análise físico-química no laboratório da UFES, cujos resultados foram $\mathrm{pH}=6,3$; umidade $=30 \% ; \mathrm{MO}=30 \%$; cinzas $=57 \%$;

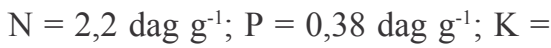
0,14 dag $\mathrm{g}^{-1} ; \mathrm{Ca}=1,10$ dag $\mathrm{g}^{-1} ; \mathrm{Mg}=$ 0,20 dag g$^{-1} ; \mathrm{Cu}=129 \mathrm{mg} \mathrm{kg}^{-1} ; \mathrm{Zn}=$ $320 \mathrm{mg} \mathrm{kg}^{-1} ; \mathrm{Fe}=41.250 \mathrm{mg} \mathrm{kg}^{-1} ; \mathrm{Mn}=$ $207 \mathrm{mg} \mathrm{kg}^{-1}$; e os metais pesados: $\mathrm{Cd}=$ $0,40 \mathrm{mg} \mathrm{kg}^{-1} ; \mathrm{Cr}=14,8 \mathrm{mg} \mathrm{kg}^{-1} ; \mathrm{Hg}=$ 4,10 $\mathrm{mg} \mathrm{kg}^{-1} ; \mathrm{Ni}=9,4 \mathrm{mg} \mathrm{kg}^{-1}$ e $\mathrm{Pb}=$ $39,7 \mathrm{mg} \mathrm{kg}^{-1}$.

O delineamento experimental foi inteiramente casualizado, com sete tratamentos e cinco repetições. A unidade experimental consistiu de um vaso de polietileno, preenchido com $6 \mathrm{dm}^{3}$ do substrato. Os tratamentos foram constituídos de: testemunha (solo) e solo+lodo de esgoto nas proporções de 33,3; 66,6; 99,9 e 133,2 $\mathrm{g} \mathrm{dm}^{-3}$. Todos os tratamentos receberam uma adubação básica com $3,33 \mathrm{~g} \mathrm{dm}^{-3}$ de superfosfato simples, incorporada aos substratos por ocasião do transplantio das mudas.

Sementes de alface do cultivar "Lívia" foram semeadas em 07/08/98, em bandejas de poliestireno contendo mistura composta por solo, areia grossa e composto orgânico. O transplante das mudas com raízes nuas foi feito após 25 dias da semeadura e a colheita, após 42 dias do transplante. As irrigações foram feitas colocando-se $300 \mathrm{ml}$ de água em cada vaso, diariamente.

As plantas foram colhidas aos 42 dias após o transplante, pela manhã, cortadas rentes à superfície dos substratos e determinada a massa seca da parte aérea e o número médio de folhas por planta (NFP). A matéria seca foi obtida após secagem em estufa de circulação forçada de ar à temperatura de $60^{\circ} \mathrm{C}$, até atingir peso constante. Posteriormente foram moídas em moinho tipo Wiley, com peneira de 20 mesh, para análise foliar onde foram determinados: $\mathrm{N}$ pelo método Kjeldahl; P pelo método colorimétrico; K pela fotometria de chama; $\mathrm{Ca}, \mathrm{Mg}, \mathrm{Mn}, \mathrm{Pb}$ pelo método de espectrofotometria de absorção atômica (Tedesco et al., 1995); e de metais pesados: $\mathrm{Cd}, \mathrm{Cr}$, Ni e Pb, de acordo com (Ure e Shand, 1974). Os dados obtidos foram submetidos à análise de regressão.

\section{RESULTADOS E DISCUSSÃO}

As análises das amostras de lodo de esgoto bruto, indicaram $\mathrm{pH}$ de 6,3 situando-se entre os valores sugeridos para que o meio não se torne extremamente seletivo para os microrganismos. Em relação à matéria orgânica foi observado o teor de $30 \%$, o teor de umidade registrado nas amostras foi de $30 \%$ e o teor de cinzas foi de $57 \%$. O teor médio de matéria orgânica de $30 \%$ está próximo do limite mínimo indicado por Kiehl (1985) para fertilizante orgânico em uso agrícola. O teor médio de $2,2 \%$ de nitrogênio verificado no lodo bruto encontra-se acima do limite mínimo exigido para a sua utilização como fertilizante orgânico. Entretanto, o teor médio de fósforo encontrado foi de $0,38 \%$, o de potássio $0,14 \%$, o de cálcio $1,1 \%$ e o de magnésio $0,2 \%$, valores considerados baixos, sugerindo a necessidade de enriquecimento desse material com uma fonte solúvel de fósforo, cálcio e magnésio. Os níveis de micronutrientes apresentaram valores próximos de outros compostos orgânicos utilizados na produção de alface por outros autores (Ricci et al., 1994; Santos et al., 1997; Vidigal et al., 1997; Rodrigues e Casali, 1998). Segundo Fernandes (1997) quando os resíduos orgânicos atendem à necessidade de nitrogênio, fornecem os micronutrientes necessário ao crescimento e desenvolvimento das plantas.

As concentrações de metais pesados foram relativamente baixas à exceção do mercúrio, cujo limite máximo encontrado foi de 4,1 $\mathrm{mg} \mathrm{kg}^{-1}$, o qual supera os limites internacionais permitidos em vários países, mas é inferior ao limite estabelecido nos EUA, de cerca de $8 \mathrm{mg}$ $\mathrm{kg}^{-1}$ (Gonçalves et al., 1997). Entretanto, deve-se considerar que a mobilidade de metais no solo dependerá da forma química sob a qual o metal se apresenta e das características do solo como $\mathrm{pH}$, teor de matéria orgânica, CTC e porcentagem de argila, que têm importância fundamental na mobilidade dos cátions metálicos (Mulchi et al., 1991).

Santos et al. (1994, 2001), trabalhando com alface cultivada com composto orgânico, verificaram que a aplicação de doses crescentes de composto orgânico 
proporcionou plantas de alface com menor teor de matéria seca. Resultados semelhantes foram observados no atual experimento (Figura 1D). Prado et al. (2002) também obtiveram aumento na produção de matéria seca da alface com a aplicação de escória de siderurgia, corrigida com calcário. Alguns autores associam aumento da massa de matéria seca dos tecidos das folhas à deficiência de nitrogênio (Primavesi, 1985; Vidigal et al., 1997). Portanto, os tratamentos com menores teores de matéria orgânica apresentaram também os menores teores de nitrogênio e foram os que apresentaram menor peso da planta inteira e menor número de folhas (Figuras 1A, 1B). Esse fato pode estar associado à deficiência desse nutriente causando redução na fotossíntese, menor crescimento e mais elevado teor de matéria seca na parte aérea (Primavesi, 1985).

Os teores de macronutrientes determinados na matéria seca das folhas de alface (Figura 2A) podem ser considerados como adequados na análise foliar das hortaliças (Magalhães, 1988). Alta disponibilidade de $\mathrm{K}$ pode reduzir a absorção de Ca e Mg (Rodrigues e Casali, 1998), que são bases trocáveis responsáveis juntamente com o Na pelas modificações de $\mathrm{pH}$ do solo (Kiehl, 1985). A utilização de matéria orgânica nas culturas pode alterar a composição mineral das plantas, isso, dependendo entre outros fatores, da fertilidade do solo (Warman, 1990), das características do material orgânico e da quantidade aplicada (Asiegbu e Oikeh, 1995). Rodrigues e Casalli (1998) verificaram maiores teores de $\mathrm{P}$ e $\mathrm{K}$ em folhas de alface adubada com composto orgânico, enquanto Amaral et al. (1994), trabalhando com escória como corretivo de solo na cultura da alface, verificaram aumento de $\mathrm{Mn}$, diferindo dos resultados obtidos por Ferraz Junior et al. (2003), onde os teores de Mn não foram afetados. Estes autores sugerem que o lodo de cervejaria tratado pode substituir o esterco de galinha, como adubo para o cultivo da alface. Ricci et al. (1994), trabalhando com composto orgânico na produção de alface, verificaram aumento de produtividade em função do tipo de adubo orgânico utilizado. Resultados semelhantes foram en-
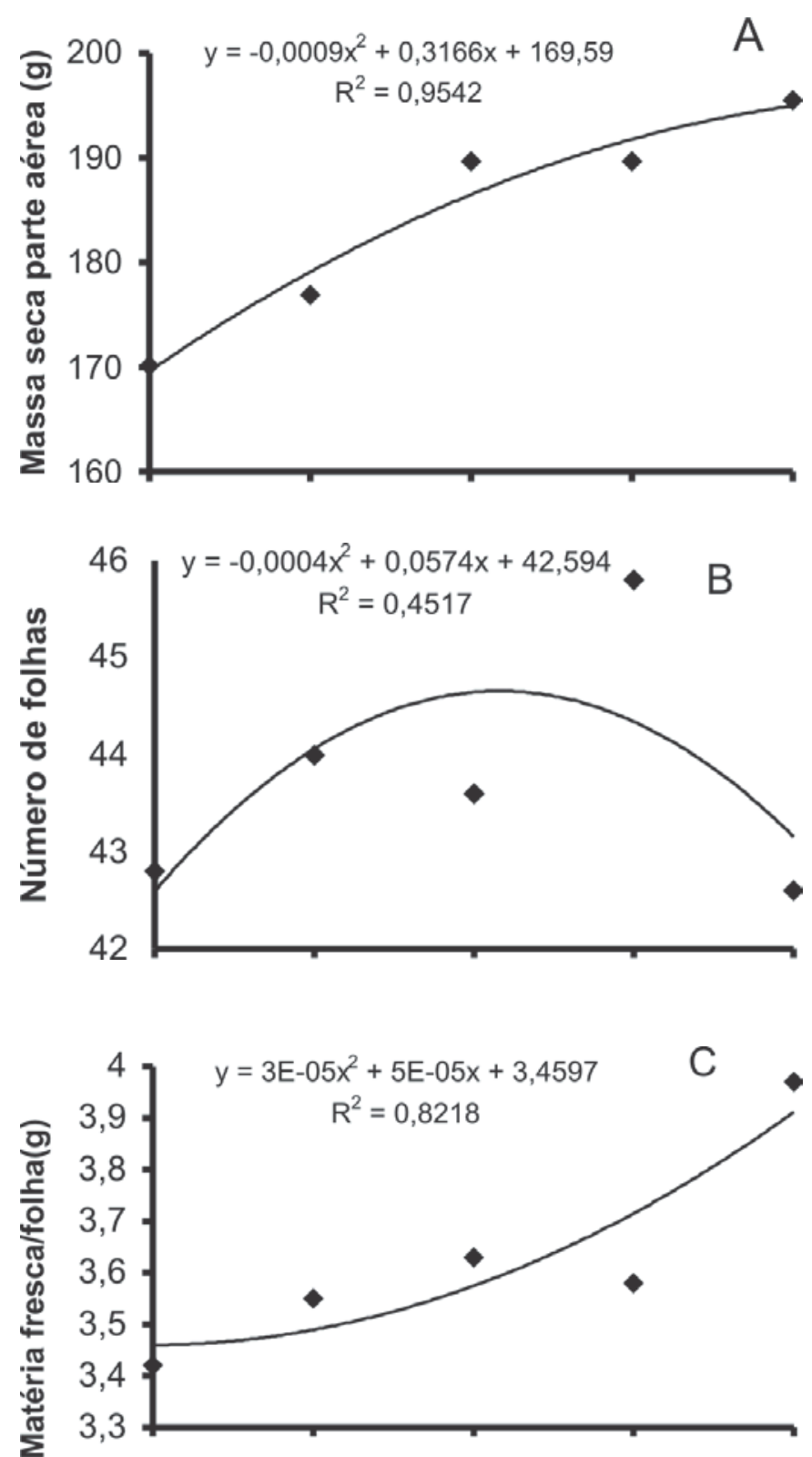

D

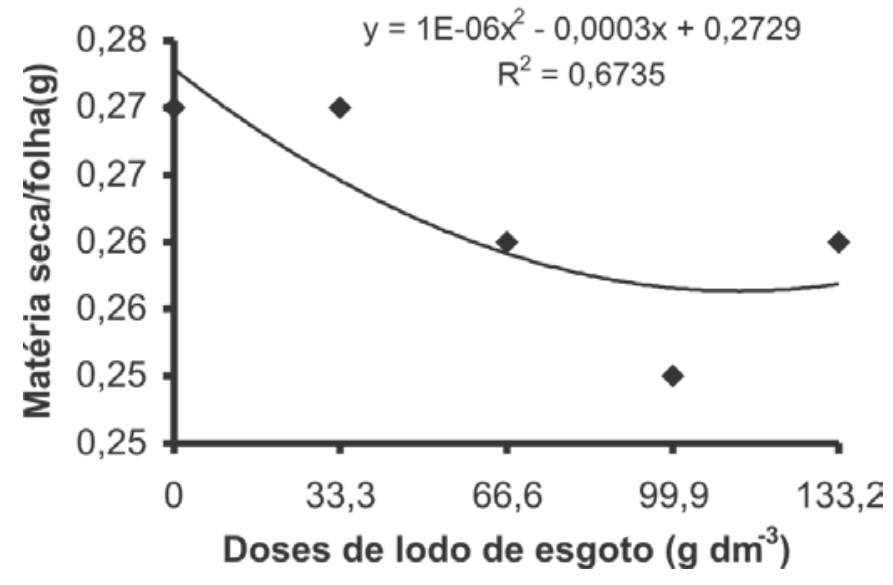

Figura 1. Médias de massa seca da parte aérea (A), número de folhas (B), matéria fresca de folhas (C) e matéria seca de folhas (D) separadamente, de plantas de alface cultivar Lívia cultivadas com lodo de esgoto. Alegre, UFES, 1999. 


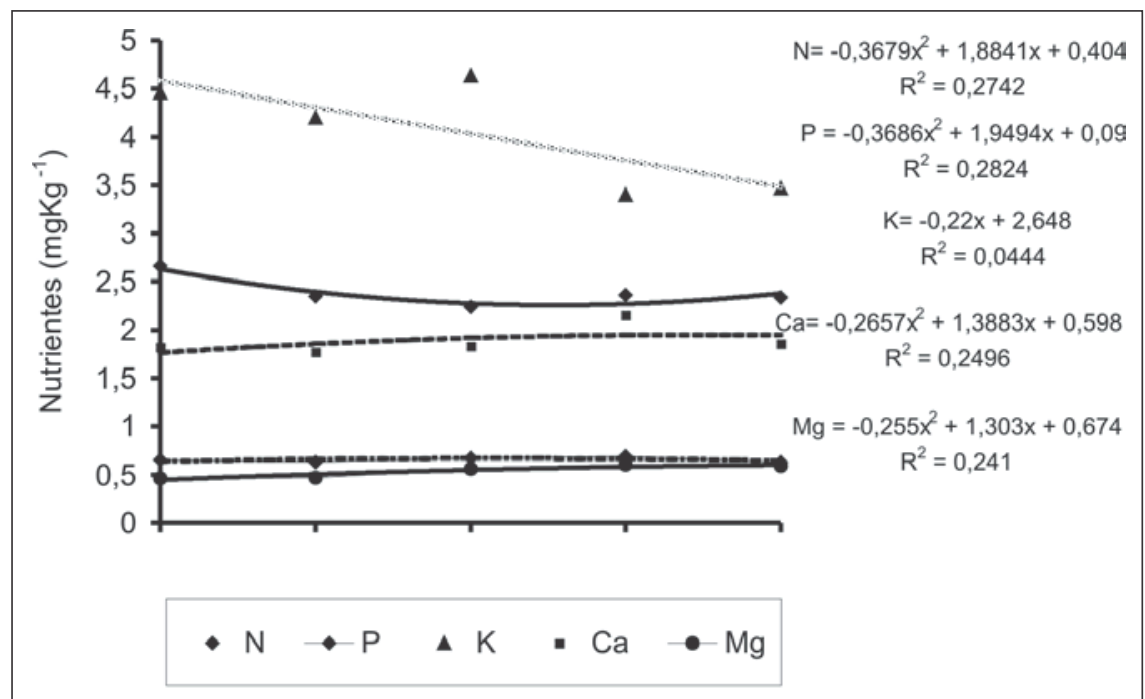

A

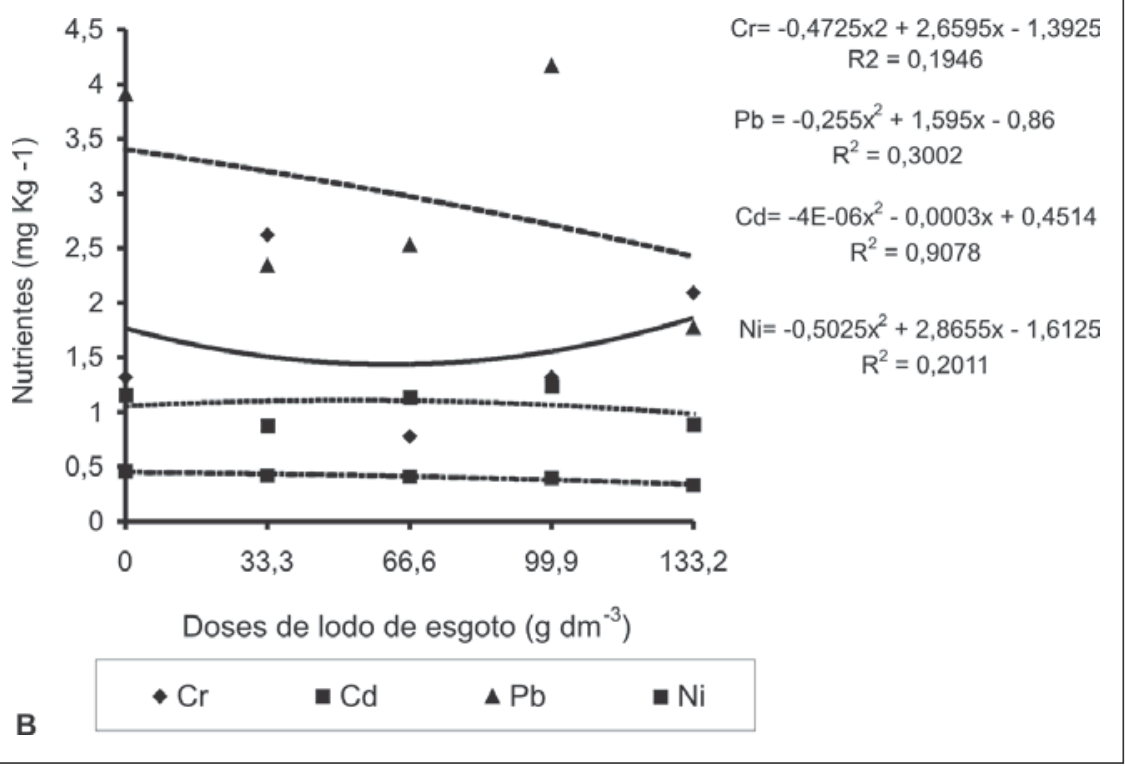

Figura 2. Teores de nitrogênio, fósforo, potássio, cálcio e magnésio (A) e de cromo, cádmio, chumbo e níquel (B) em folhas de alface cultivar Lívia cultivadas com lodo de esgoto. Alegre, UFES, 1999.

contrados na cultura do pimentão (Mello, et al., 2000; Ribeiro, et al., 2000). Os teores de N, para as diferentes dosagens de lodo de esgoto, encontram-se próximos da média do respectivo intervalo proposto por Magalhães (1988). Na cultura da alface, a utilização de fertilizantes orgânicos de lenta solubilização e contendo alta concentração de nitrogênio é mais eficiente para o crescimento e desenvolvimento (Katayama, 1993). Os teores de P, K e Ca encontram-se acima do limite superior do intervalo proposto para todos os tratamentos. Resultados semelhantes foram encontrados por Ferraz Junior et ção Brasileira da Indústria de Alimentos, 1985). Por outro lado, de acordo com McBride (1994), quando os metais pesados se encontram em baixas concentrações, há tendência de que eles permaneçam retidos no solo pelo processo de adsorção. Silva et al. (2001) verificaram que, embora o lodo de esgoto provoque aumento nos teores de metais pesados no solo, estes perduram por apenas um ano e em níveis aquém dos valores considerados nocivos ao ambiente. Sob condições naturais, a presença desses metais pesados no solo não tem causado danos às plantas e animais, fato que pode estar associado à formação de complexos estáveis com ácidos húmicos ou a formação de óxidos e hidróxidos, causando redução na sua disponibilidade (Miyazawa, et al., 1999).

Considerando os resultados obtidos, pode-se concluir que em solos com características similares às deste experimento, o lodo de esgoto com as características daquele empregado neste experimento, com o $\mathrm{pH}$ corrigido para a faixa ideal e com saturação de bases para $70 \%$, pode ser utilizado como fertilizante agrícola para o cultivo da alface.

\section{AGRADECIMENTOS}

Aos funcionários da Superintendência de Abastecimento de Água e Esgoto de Jerônimo Monteiro, pela colaboração na coleta de material; a CAPES/ PROLAG, pela bolsa concedida e apoio financeiro ao segundo curso de Pós-Graduação em Agroecologia do CCA-UFES.

\section{LITERATURA CITADA}

AMARAL, A.S.; DEFELIPO, B.V.; COSTA, L.M.L.; PONTES, M.P.F. Liberação de Zn, Fe, $\mathrm{Mn}$ e Cd de quatro corretivos de acidez e absorção por alface em dois solos. Pesquisa Agropecuária Brasileira, Brasília, v.29, n.9, p.1351-1358, 1994.

ANDREOLI, C.V; DOMASZK, S; FERNANDES, F.; LARA, A.I. Proposta preliminar de regulamentação para a reciclagem agrícola do lodo de esgoto no Paraná. Sanare, Curitiba, v.7, n.11, p.53-60, 1997.

ANDREOLI, F.N.; IHLENFELD, R.G.; TEIXEIRA, E.C. Bacia de infiltração como alternativa de reuso da água e tratamento de esgoto sanitário, na remoção de DQO, SS e Nitrogênio. Sanare, Curitiba, v.11, n.11, p.9-18, 1999.

ASIEGBU, J.E.; OIKEH, S. Evaluation of chemical composition of manures from different organic wastes and their potential for supply of nutrients to tomato in a tropical Ultisol. Biological Agriculture Horticulture, v.12, p.47-60, 1995. 
ASSOCIAÇÃO BRASILEIRA DA INDÚSTRIA DE ALIMENTOS (São Paulo, SP). Compêndio da legislação dos alimentos. São Paulo, 1985. Não paginado.

BISCAIA, R.C.M.; MIRANDA, G.M. Uso de lodo de esgoto calado na produção de milho. Sanare, Curitiba, v. 5, n.1, p.86-89, 1996.

FERNANDES, F. Lodo em estação de tratamento de água e esgoto. Engenharia Sanitária e Ambiental, v.2, n.1, p.169, 1997.

FERRAZ JUNIOR, A.S.L.; SOUZA, S.R.; CASTRO, S.R.P.; PEREIRA, R.B. Adubação de alface com lodo de esgoto de cervejaria. Horticultura Brasileira, Brasília, v.21, n.1, p.60-63, 2003. FERREIRA, M.E.; CASTELANE, P.D.; CRUZ, M.C.P. Nutrição e adubação de hortaliças. São Paulo: POTAFOS, 1993. $480 \mathrm{p}$.

FILGUEIRA, F.A.R. Novo manual de agrotecnologia moderna na produção e comercialização de hortaliças. Viçosa: UFV, 2000. $402 \mathrm{p}$.

GONÇALVES, R.F.; NASCIMENTO, C.G.; FERRARI, G.F.; MULLER, P.S.G. Lodo de lagoas de estabilização em operação no Espírito Santo: formação e características. In: CONGRESSO BRASILEIRO DE ENGENHARIA SANITÁRIA E AMBIENTAL, 19, 1997, Foz do Iguaçu. Anais. Foz do Iguaçu: ABES, 1997, p.427-437.

KATAYAMA, M. Nutrição e adubação de alface, chicória e almeirão. IN: NUTRIÇÃO E ADUBAÇ̃̃O DE HORTALIÇAS. Piracicaba. Associação Brasileira para Pesquisa da Potassa e do Fosfato. p.141-148, 1993.

KIEHL, E.J. Fertilizantes orgânicos. São Paulo: Ceres, 1985, $492 \mathrm{p}$.

LOURENÇO, R.S.; ANJOS, A.R.M.; LIBARDI, P.L.; MEDRADO, M.J.S. Efeito do lodo de esgoto na produtividade de milho e feijão, no sistema de produção da bracatinga. Sanare, Curitiba, v. 5 , n.5, p. 90-92, 1996.

MAGALHÃES, J.R. Diagnose de desordens nutricionais em hortaliças. Brasília, EMBRAPA, DPV, 1988, 64 p.

MALAVOLTA, E. Fertilizantes e seu impacto ambiental: micronutrientes e metais pesados, mitos, mistificação e fatos. São Paulo: Prodquímica, 1994. $153 \mathrm{p}$.

McBRIDE, M.B. Environmental chemistry of soils. New York: Oxford University, 1994. 406 p. MELLO, S.C.; PEREIRA, H.S.; VITTI, G.C. Efeitos de fertilizantes orgânicos na nutrição e produção do pimentão. Horticultura Brasileira, Brasília, v.18, n.3, p.200-203, 2000.
MIYAZAWA, M.; GIMENEZ, S.M.N.; FERNANDES, F.; OLIVEIRA, E.L.; SILVA, S.M.C.P. Efeito do lodo de esgoto nos teores de metais pesados no solo e na planta. In ANDREOLI, C.V.; LARA, A.I.; FERNANDES, F. Reciclagem de biossólidos: transformando problemas em soluções. Curitiba: Sanepar/Finep, 1999. p.204-225.

MULCHI, C.L.; ADAMU, C.A.; BELL, P.F.; CHANEY, R.L. Residual heavy metals concentrations in sludge-amended coastal plain soils. I. Comparison of extractants. Communications in Soil Science and Plant Analysis, v.22, n.9-10, p.919-941, 1991.

PRADO, R.M.; COUTINHO, E.L.M.; ROQUE, C.G.; VILLAR, M.L.P. Avaliação da escória de siderurgia e de calcários como corretivos da acidez do solo no cultivo da alface. Pesuisa Agropecuária Brasileira, Brasília, v.37, n.4, p.539-546, 2002.

PRIMAVESI, A. Manejo ecológico do solo: a agricultura em regiões tropicais. 8.ed. São Paulo: Nobel, 1985. $541 \mathrm{p}$.

RAIJ, B. A capacidade de troca de cátions das frações orgânica e mineral dos solos. Bragantia, Campinas, v.2, n.8, p.85-112, 1969.

RAIJ, B. Avaliação da fertilidade do solo. Piracicaba: Instituto da Potassa e Fosfato, 1987. 142 p.

RIBEIRO, L.G.; LOPES, J.C. MARTINS-FILHO, S.; RAMALHO,S.S. Adubação orgânica na produção de pimentão. Horticultura Brasileira, Brasília, v.18, n.2, p.134-137, 2000.

RICCI, M.S.; CASALI, V.W.D,; CARDOSO, A.A.; RUIZ, H.A. Produção de alface adubadas com composto orgânico. Horticultura Brasileira, Brasília, v.12, n.1, p.56-58, 1994.

RODRIGUES, E.T.; CASALI, V.W. Resposta da alface à adubação orgânica. II. Teores, conteúdos e utilização de macronutrientes em cultivares. Revista Ceres, UFV, Viçosa, v.45, n.261, p.437449, 1998.

SANTOS, R.H.S. Crescimento, produção e qualidade de alface (Lactuca sativa L.) cultivada com composto orgânico. 1993. 114 p. (Tese mestrado) - UFV, Viçosa.

SANTOS, R.H.S.; CASALI, V.W.D.; CONDÉ, A.R.; MIRANDA, L.C.G. Qualidade de alface cultivada com composto orgânico. Horticultura Brasileira, Brasília, v.12, n.1, p.29-32, 1994.

SANTOS, I.C., CASALI, V.W.D.; MIRANDA,G.V. Teores de metais pesados de potássio e de sódio no substrato após o cultivo de dez cultivares de alface. Revista Ceres, Viçosa, v.44, n.251, p.53-62, 1997.
SANTOS, I.C.; CASALI, V.W.D.; MIRANDA, G.V. Teores de metais pesados, $\mathrm{K}$ e $\mathrm{Na}$, no substrato, em função de doses de composto orgânico de lixo urbano e de cultivares de alface. $\mathrm{Ci}$ ência Rural, Santa Maria, v.29, n.3, p.415-421, 1999.

SANTOS, R.H.S.; SILVA, F.; CASALI, V.W.D.; CONDÉ, A.R. Efeito residual de adubação com composto orgânico sobre o crescimento e produção de alface. Pesquisa Agropecuária Brasileira, Brasília, v.36, n.11, p.1395-1398, 2001.

SILVA, F.C.; BOARETTO, A.E.; BERTON, R.S.; ZOTELLI, H.B.; PEXE, C.A.; BERNARDES, H.M. Pesquisa Agropecuária Brasileira, Brasília, v.36, n.5, p.831-840, 2001.

SOCCOL, V.T.; PAULINO, R.C.; CASTRO, E.A. Agentes patogênicos: helmintos e protozoários. In: ANDREOLI, C.V.; LARA, A.I.; FERNANDES, F. (Org) Reciclagem de biossólidos: transformando problemas em soluções. Curitiba: Sanepar, Finep, 1999. p.156-179.

TEDESCO, M.J.; GIANELLO, C.; BISSANI, C.A.; BOHNEN, H.; VOLKWEISS, S.J. Análise de solo, plantas e outros materiais. $2^{\mathrm{a}}$ ed. Porto Alegre: Departamento de solos, UFRGS, 1995. 174 p. (Boletim Técnico, 5).

URE, A.M.; SHAND, C.A. The determination of mercury in soils and related materials by cold vapor atomic absorption spectrometry. Analytica Chimica Acta, v.2, 1974

VIDIGAL, S.M.; RIBEIRO, A.C.; CASALI, V.W.D.; FONTES, L.E.F. Resposta da alface (Lactuca sativa L.) ao efeito residual da adubação orgânica. I - Ensaio de Campo. Revista Ceres, Viçosa, v.42, n.239, p.80-88, 1995.

VIDIGAL， S.M.; SEDIYAMA，M.A.N.; GARCIA, N.C.P.; MATOS, A.T. Produção de alface cultivada com diferentes compostos orgânicos e dejetos suínos. Horticultura Brasileira, Brasília, v.15, n.1, p.35-39, 1997.

VIGGIANO, J. Produção de sementes de alface. In: CASTELLANE, P.D.; NICOLOSI, W.M.; HASEGAWA, M. (Ed.). Produção de sementes hortaliças. Jaboticabal: FCAV/FUNEP, 1990, p.1-13. WARMAN, P.R. Fertilization with manures and legume intercrops and their influence on Brassica and tomato growth, and on tissue and soil copper, manganese and zinc. Biological Agriculture Horticulture, v.6, p.325-335, 1990. 